\title{
BYOB: How Bringing Your Own Shopping Bags Leads to Treating Yourself, and the Environment
}

\section{Citation}

Karmarkar, Uma R., and Bryan Bollinger. "BYOB: How Bringing Your Own Shopping Bags Leads to Treating Yourself, and the Environment." Journal of Marketing 79, no. 4 (July 2015): 1-15.

\section{Published Version}

http://journals.ama.org/doi/full/10.1509/jm.13.0228

\section{Permanent link}

http://nrs.harvard.edu/urn-3:HUL.InstRepos:28548033

\section{Terms of Use}

This article was downloaded from Harvard University's DASH repository, and is made available under the terms and conditions applicable to Open Access Policy Articles, as set forth at http:// nrs.harvard.edu/urn-3:HUL.InstRepos:dash.current.terms-of-use\#OAP

\section{Share Your Story}

The Harvard community has made this article openly available.

Please share how this access benefits you. Submit a story.

Accessibility 


\section{BYOB: How Bringing Your Own Shopping Bags Leads to Treating Yourself, and the Environment}

As concerns about pollution and climate change become more mainstream, there has been a rise in the belief that shopping with reusable grocery bags is an important environmental and socially conscious choice. In parallel, firms have been joining policymakers in using a variety of initiatives to reduce the use of disposable plastic bags. However, little is known about how these initiatives might alter other elements of consumers' in-store behavior. Using scanner panel data from a single California location of a major grocery chain, and controlling for consumer heterogeneity, we demonstrate that bringing your own bags increases purchases of not only environmentally friendly organic foods, but also indulgent ones. We use experimental methods to further explore the expression of these effects and to consider the effects of potential moderators, including competing goals and store policies. Our findings have implications for decisions related to product pricing, placement and assortment, store layout, and the choice of strategies employed to increase the use of reusable bags. 
Attention to environmental concerns has been steadily increasing in mainstream media, along with education about environmental issues and the use of policies designed to encourage "green" behaviors. In particular, significant efforts have been made to promote the adoption of reusable shopping bags. Local, city, and even country-level governments have taken steps to ban retail use of disposable plastic bags, or to require businesses to charge for giving them out (Galbraith 2012, Wang 2013). For example, by 2011, twenty-eight U.S. cities, including New York, NY and San Francisco, CA, had enacted some form of ban, fee, or other regulation on the use of "thin-film" disposable shopping bags. In September of 2014, California became the first state to ban single-use plastic bags (Chappell 2014).

There are obvious financial reasons why firms might encourage consumers to bring their own bags in lieu of stores stocking and providing disposable plastic ones. Some stores currently promote the use of reusable bags by selling them directly, giving them away, and/or offering financial and social incentives for shoppers who bring them (Smith, 2007; Stern 2007, O’Donnell 2010). Depending on the community, it is likely that significant social approval and developing norms support this behavior as well.

An interesting question then arises: would introducing reusable bags have a measurable influence on individuals' shopping behavior? A recent survey of U.S. consumers found that 29 percent had utilized their own reusable bags during their most recent shopping trip (Food Shopper Insights, 2011). This reflects a sizeable adoption of the practice, but also indicates that the behavior is not routine for most people, and may be inconsistent between trips. In contrast to more habitual parts of grocery shopping, the act of bringing a bag may be distinct, novel, or notable enough to carry meaning for consumers in a way that influences purchase decisions. 
While several such influences are possible, behavioral theory is unclear in predicting which direction they might take. For example, a consumer's awareness that they brought their own grocery bags could make environmentally friendly items more salient, evoke goals of making green choices in general, or evoke goals of being a virtuous person who takes morally responsible actions. However, it is similarly possible that by bringing a bag, shoppers would feel they had already taken measures to progress towards these goals. Thus, while consumers might make more purchases consistent with being green and/or good, perceived goal progress could also lead them to shirk environmentally in later choices. In addition, while it is intuitive that a green choice might influence green purchases, bringing one's own bags has the potential to influence other choices as well. Since doing so might feel like making a virtuous choice, consumers could feel licensed to make other less virtuous, or more indulgent, decisions afterwards (Fishbach and Dhar 2005, Khan and Dhar 2006).

In this article, we provide some of the first evidence demonstrating that the act of bringing one's own grocery bags causes significant changes in food purchasing behavior. Our studies examine this issue by combining empirical and experimental methods. The former allows us to demonstrate our central effects of interest in a robust manner with real world data. The latter is used to strengthen our understanding of these results in a setting where causality can be established, and to build on it by testing hypotheses about specific moderating factors.

In Study 1, using Logistic regression, we conduct multiple analyses at the shopping basket level of consumer purchasing data from a single location of a major grocery store chain. We include extensive controls for consumer heterogeneity and unobserved promotional activity. In accordance with our hypotheses, (developed further below), we examine how purchases of organic and indulgent foods can be increased by bringing one's own bags. Study 2 tests how 
bringing a bag influences consumers' self-generated consideration sets, and how having to consider the preferences of others (e.g. dependents), might moderate those influences. In Studies 3 and 4, we look at whether our effects depend on the reasons shoppers might bring their own bags, including store policies, as well as the impact of cost as a competing factor with our effects. Our findings have implications for firm decisions regarding product placement and pricing, as well as their strategy for promoting (or not promoting), the use of reusable bags.

\section{Theoretical Background}

\section{Priming Effects and Consistent Behavior}

Consumers are subject to a number of external influences in nearly any shopping context. For example, exposure to various types of experiences or information can increase the accessibility of related mental constructs (see Schacter and Buckner 1998 for review). This priming effect can also occur with personal characteristics or goals, such that once they are made more salient, they can encourage consistent subsequent behavior (e.g. Bargh et al. 2001, Shah 2005, Wheeler and DeMarree 2009). Bringing one's own bags to the grocery store could motivate more consideration of green options by priming environmental thoughts and/or activating a broader goal to help the environment.

How might this desire to make green decisions express itself in a grocery shopping context? While different types of stores in different locations offer a number of products that are relevant to environmental concerns, food purchases are a common element across grocery shopping experiences. In this domain, consumers perceive organic foods to be more environmentally beneficial than conventional foods (for review, see Yiridoe et al. 2005; Hughner 
et al. 2007; Shafie and Rennie, 2012.) In particular, organic foods are most commonly perceived to involve lower levels of pesticides (e.g. Yiridoe et al. 2005), in accordance with the definitions used for USDA organic certification.

Based on these consumer perceptions, we chose to examine possible green effects of bringing one's bags by examining purchases of organic foods.

\section{H1: When consumers bring their own bags for grocery shopping, they will be primed to choose more organic items, when such options are available.}

As suggested above, reusable bags could also prime consumers' general motivations to behave in a good or virtuous manner, which might be expressed via taking positive environmental actions. Increases in organic food purchases are consistent with this, as they are perceived to be both more natural and more moral (e.g. Mazar and Zhong, 2010; Eskine 2013), and are marketed using messages that support these perceptions. Thus our hypothesis focuses primarily on the purchasing behavior that results from bringing a bag, as opposed to identifying the specific motivation (being green or being moral) that the bag could prime.

\section{Licensing Effects and Contrasting Behavior}

While priming encourages consistent behavior, other psychological mechanisms might prompt contrasting behavior in this situation. For example, awareness of having made progress towards a goal or having taken a virtuous action can cause people to feel they have earned a more indulgent reward (e.g. Kivetz and Simonson, 2002). These actions can unconsciously license subsequent indulgences (Fishbach and Dhar 2005, Khan and Dhar 2006). In particular, Khan and Dhar (2006) showed that one instance of virtuous self-signaling, that is, boosting one's 
self-concept via a virtuous action or expression of intent, could increase the likelihood of

choosing a luxury item over a necessity in a subsequent unrelated choice. In this vein, Mazar and Zhong (2010) demonstrated that when individuals consider green purchases such as organic food, they feel virtuous for taking a socially and environmentally positive action and are more likely to lie or show other negative moral behavior afterwards.

Studies of licensing effects have generally presented participants with specific sequences of unrelated decisions, which are composed of distinct and explicit tradeoffs. Very little of this research has explored self-guided open-ended choices that fall within a single overarching context. Since the nature of grocery store shopping allows for unplanned purchases, we propose that it will permit or facilitate licensing-type effects by offering shoppers who bring their own bags a channel to make indulgent choices.

\section{H2: When consumers bring their own bags for grocery shopping, they will be licensed to purchase more indulgent products.}

\section{Dependents' Influence on Grocery Choices}

If a person is shopping for a family, feelings of parental responsibility and the preferences of his or her children may supersede his or her own conscious and/or subconscious preferences. Previous work has shown that children do exert a distinct influence on grocery basket composition, most strongly for products that they use or find relevant to their own needs (Mangleburg 1990, Martensen and Gronholdt 2008). We can consider some of the ways having children might affect a shopper's purchases of organic or indulgent foods in particular.

Upon the arrival of a baby in the household, parents may initiate or increase their purchases of organic food (Hill and Lynchehaun, 2002). More generally, households with 
children are more likely to buy organic items than those without (Thompson and Kidwell, 1998). On the one hand, if parents have a preexisting motivation to purchase organic foods or a habit of doing so, there may be a ceiling effect, such that bringing one's own bag has no additional influence. On the other hand, it is also possible that holding a strong motivation to buy organic makes parents more sensitive to primes like a reusable bag.

In terms of indulgences, though children can increase their parents' health conscious choices (Prasad et al. 2008), they can also increase their purchases of indulgent snack foods (Marshall et al. 2007). Furthermore, children's wants and needs (and the degree of influence they hold) are likely to vary significantly between households. Thus, while having children is likely to have its own set of influences on indulgent choices, it may increase or decrease such purchases. As such, we propose the following:

\section{H3: Shoppers whose households include children (dependents) will show less of an influence of bringing their own bags on organic purchases and indulgent purchases.}

Broadly speaking, this hypothesis suggests that any effects of priming or licensing mechanisms on shoppers' preferences could be diluted, or even overpowered, by a range of competing motivations arising from their role as parents.

\section{Competing vs. Parallel Mechanisms}

Even with the moderation predicted by $\mathrm{H} 3$, it is worth considering the implications of $\mathrm{H} 1$ and $\mathrm{H} 2$ as a pair, since these behavioral effects might seem to conflict or otherwise interact. For example, organic foods are perceived to have health benefits in addition to their environmental benefits (e.g. Yiridoe et al. 2005; Hughner et al. 2007; Shafie and Rennie, 2012). Thus 
consumers who fill their baskets with these healthy items might feel more guilt or conflict when tempted by an indulgence. This conflict might suggest that consumers who brought their bags would buy more organic or more indulgent foods, but not both. A second possibility is that purchasing "good" healthy, organic food is actually the factor that increases indulgent choices. Bringing bags might increase organic purchases, which in turn licenses shoppers to increase indulgent purchases.

However, we propose that the act of bringing a bag can interact in different ways with different choices. During the course of a shopping trip, individual decisions do not have to be linked as direct comparisons or tradeoffs. In addition to serving a general purpose (e.g. restocking the pantry or eating healthily), products can be selected as part of a specific list (e.g. the ingredients for one recipe), or bought entirely independently of one another. Shoppers are able to choose a portfolio of items that reflect multiple goals. Thus our empirical and experimental work directly tests the following hypothesis:

\section{H4A: Bringing one's own bags increases organic and indulgent grocery purchases through separable pathways (e.g. priming and licensing mechanisms) with separable outcomes.}

H4A reflects the fact that we posit two different underlying mechanisms to explain why bringing a bag might increase purchases of organic and indulgent items. That is, while priming and licensing can both influence or evoke motivations, they do so in different ways. For example, a central feature of the work on licensing is that the initial virtuous choice is self-motivated. If the reasons for an individual's "virtuous action" can be attributed to other people or external policies, then its subsequent influence is significantly attenuated (Khan and Dhar 2006). In contrast, priming can arise from objects or information in a person's surroundings, regardless of any 
personal impetus or self-attribution for their presence (e.g. Dijksterhuis et al. 2005). This "agency" or "self-attribution" requirement of licensing is a useful way to support our proposed mechanism for how bags increase indulgent purchases. Furthermore, since it does not apply to priming, it offers a way to test the "separability" of the effects of the bag on organic and indulgent foods. This leads to an additional conjecture:

\section{H4B: Attributing bringing one's own bags to the store will decrease purchases of indulgent (but not organic) products, as compared to attributing bringing bags to the self.}

This line of inquiry is a particularly relevant concern for managers, given that legislation mandating the use of one's own bags, or instituting charges for store bags, is slowly but increasingly being put into place (Galbraith 2012; Chappell 2014). We explore this issue directly in Studies 3 and 4.

\section{The Influence Of Costs}

Our proposed effects have a literal cost - choosing to "buy organic" in a category or adding an (unplanned) indulgence to the basket typically increases how much a shopper spends. For example, organic groceries are generally offered at a price premium compared to their nonorganic counterparts. In our empirical analyses, it is thus important to control for price. Further, even if bringing a bag makes consumers more willing to purchase these kinds of foods, that effect might be countered by the salience of the added cost.

While it is possible to imagine that individuals who are willing to buy organic belong to a relatively price insensitive segment, previous analyses have shown that the number of consumers willing to pay a premium for organic foods decreases as the level of that premium increases 
(Yiridoe et al. 2005). With regards to indulgences, though they can be relatively inexpensive, they often inspire a sense of guilt and a subsequent need for justification (e.g. Okada 2005). This could similarly increase sensitivity to costs or price information. Furthermore, previous work suggests that making payments more immediate, and thus more salient, decreases the likelihood of spending on indulgences (Prelec and Loewenstein, 1998). Indeed, studies showed that increasing the immediacy of costs by using cash (as opposed to credit cards, which defer payment) decreased shoppers' likelihood of buying indulgent or "vice" foods (Thomas et al. 2011). Finally, there is evidence for the converse effect: framing a hedonic item's price as a discount (e.g. lowering costs) can offer consumers a justification for buying, and thus increase the likelihood of its purchase (Khan and Dhar 2010). Based on this evidence, we propose the following:

\section{H5: Increasing the salience of additional costs will decrease the effects of bringing one's own bags on both organic and indulgent purchases.}

Note here that salience refers to the significance of costs in the decision-making process. Thus it could arise from the relative amount of cost-indicating price information available, attention paid to the price, or level of the price, with higher price premiums being more salient.

Across four studies, we combine results from empirical and experimental data to demonstrate that the simple choice to bring one's own grocery bags can significantly alter shopping behavior. We provide evidence for multiple psychological mechanisms working in parallel to create these effects, and to illustrate some of the factors that bound their impact. Our findings have implications for firms' optimal strategy in encouraging the use of reusable bags, and speak to the managerial question of how various legal policies and incentive programs 
already in place might direct shopper behavior. Thus our paper provides insight into a relatively new consumer behavior with potentially large ramifications for indulgent impulse purchases and higher priced (often higher margin) organic purchases.

\section{Study 1: Empirical Analysis of Grocery Loyalty Card Data}

To best investigate our hypotheses in a real-world situation, we examined loyalty cardholder data from one location of a major grocery retailer chain. This chain is not one that specializes in organic products. The data are for a single store in California from May 29, 2005 through March 31, 2007. During this time period, no government or store policies placed requirements or restrictions on the use of thin-film plastic bags (or reusable bags). Both plastic and paper bags were offered for free at the register, and shoppers were under no legal or storewide obligations to use a particular option. The store did offer a very small $(\$ 0.03)$ credit for each bag the shoppers themselves provided. Thus, for each trip, the data included information about whether or not the consumer brought his or her own bags and/or purchased a reusable bag, allowing us to track effects on purchasing by the same households over time.

The data reflect a total of 2,071,302 shopping trips by 59,659 households. ${ }^{1}$ Figure 1 shows a histogram of the daily timing of these trips, and reveals that most trips were made between 6 AM and 10 PM. For the analysis, we dropped the 27,549 transactions outside of this time window, when factors such as sleep deprivation could confound the effects of interest. 
In this work, we propose that the act of bringing a bag on a shopping trip causes changes in shopper behavior on that trip. One of the most convincing ways to demonstrate this in our data, which spans several months, is to compare the same households on trips during which they did bring a bag to trips on which they didn't (e.g. "within-household"). This avoids potential unobserved outside sources of heterogeneity, which could arise from simply comparing separate populations of households that brought bags to those that didn't at all. To ensure that our analyses included enough repeated transactions for each household used, we restrict the sample to the set of households in the top ten percentile of total shopping trips (those that made at least 80 trips over the 96 weeks of data). ${ }^{2}$ Since these households are the frequent shoppers, they comprise almost half of the shopping trips in the data. We then exclude the 85 percent of households who never bring bags. The remaining sample is quite large, including 884 households and 142,938 total trips across nearly two years. The unit of analysis is the shopping basket.

Trip-level statistics relating to the categories of interest for our analyses are summarized in Table 1. While grocery stores offer a tremendous range of items in categories as diverse as health care, entertainment, and pet supplies, we focused our analysis specifically on the domain of food items as the central good of interest in this setting. This aids in our ability to generalize our results, since the availability of non-food items likely varies significantly between retailers. Food categories are defined in the data by the grocery chain, and include, for example, "bananas", "yogurt", and "cookies". ${ }^{3}$ We additionally calculate a price index for organic and non-organic produce by taking the daily average price of all purchased organic and non-organic produce products. We define $\Delta p_{t}$ as the difference of the two indices, i.e. the average organic price premium for organic produce relative to non-organic produce. 
Finally, one of our hypotheses is that the effects of bringing a bag will be attenuated in households with dependents (H3). Although this kind of demographic information is not available in the loyalty card data, it is possible to create a conservative approximation of those families with very small children. We determined that of the 884 households under consideration, 503 did not make any purchases in the baby food or baby care categories (see Appendix W1) while 182 households purchased products in these categories at least two percent of the time. (The findings reported are robust to a range of cutoff values.) As a result, though we do not have definitive data specifying whether the households include children, we can identify two distinct sets of households based on their trip history. ${ }^{4}$

\section{Organic Purchases}

Although some categories can include organic and non-organic products, in this firm's data, organic fruits and organic vegetables have their own defined categories due to the number of products and the frequency at which consumers purchase the organic option. On average, transactions contain organic produce 5.6 percent of the time (see also Table 1). To test the effects of bringing a bag, we focus our attention on whether or not the transaction includes the purchase of organic produce.

We use a random utility model in which the utility of purchasing organic produce is:

$$
u_{i t}(\text { has organic produce })=\mu_{i t}+\epsilon_{i t}
$$

and we define the mean utility $\mu_{i t}$ as:

$$
\mu_{i t}=\alpha B_{i t}+\gamma \Delta p_{t}+X_{i t} \beta_{i}+\zeta_{h}+\vartheta_{d}+\eta_{w}+\xi_{i}
$$

The unit of observation is trip $t$ by consumer $i$. Each trip $t$ is made at some hour, $h$, on day of the week, $d$, during week in the data, $w$. Bit is a dummy variable indicating whether the consumer 
brought a bag, and $\Delta p_{t}$ is the average organic price premium. $X_{i t}$ is a vector of variables used to control for the size of the shopping basket and whether or not the trip was planned. These include dummy variables for the number of non-indulgent items purchased (in ranges of five), the days since the last shopping trip, and its quadratic. We completely control for households' propensity to purchase organic items by including a dummy variable for every household. We additionally control for promotional activities and time-dependent purchasing patterns through the use of the time (hour, day, week) dummy variables. If we assume that $\epsilon_{i t}$ is distributed type 1 extreme value, then the probability of purchasing organic produce can be written as the familiar Logistic expression:

$$
\operatorname{Pr}_{i t}\left(Y_{i t}\right)=\frac{\exp \left(\mu_{i t}\right)}{1+\exp \left(\mu_{i t}\right)}
$$

We estimate the model using Logistic regression in which the dependent variable, $Y_{i t}$, is an indicator for whether the shopping basket has organic produce. ${ }^{5}$ Estimation proceeds via full maximum likelihood estimation. ${ }^{6}$ Results for the coefficients of interest are shown in the first column of Table 2. The positive and significant "bag" coefficient demonstrates that the presence of a bag increases the probability of making organic purchases, supporting H1. As expected, the significant, negative coefficient on organic price premium $\left(\Delta p_{t}\right)$ indicates that consumers are generally less likely to purchase organic products if the organic markup is higher. ${ }^{7}$

\section{Insert Table 2 About Here}

While the effects of bringing a bag are significant across the full sample, we can also use our conservative categorization of households with children to test whether or not having young dependents interacts with our main effect $(\mathrm{H} 3)$. For this analysis, we modified the mean utility in equation (2) to include interactions between a dummy variable for having children and the 
variable for bringing a bag (as well as the price premium variable.) As shown in the second column of Table 2 , the interaction between having children and bringing a bag was not significant. Thus there is no evidence that having children moderates the effects of bringing bags on organic purchases.

\section{Indulgent Purchases}

For the purposes of these analyses and the experiments that follow, we define indulgent foods as those with unambiguously high fat and/or high sugar/salt contents, high palatability (e.g. good tasting), and generally low nutritional value per calorie. As such, indulgent items are selfdefined categories such as candy or snack chips. The shopping trips in our analyses include indulgent categories 18.7 percent of the time (Table 1).

To test the effects of bringing bags on indulgent purchases, we assume a mean utility of:

$$
\mu_{i t h}(\text { has indulgent })=\alpha B_{i t h}+X_{i t} \beta_{i}+\zeta_{h}+\vartheta_{d}+\eta_{w}+\xi_{i},
$$

The explanatory variables in the mean utility expression are defined in the same manner as in the organic purchase analysis, and we use Logistic regression following equation (3) in which the dependent variable is now an indicator as to whether the trip had any of the indulgent items from the categories in Table 1. Regression results for the coefficients of interest are shown in the first column of Table 3 . The significant positive coefficient on bringing one's own bags directly addresses H2, showing that brought bags do spur an increase in purchases of indulgent items. ${ }^{7}$

\section{Insert Table 3 About Here}

We test the moderating effect of children by modifying equation (4) to include an interaction between the key variable of interest (e.g. bringing a bag) with whether or not the 
household has young children. Results are shown in the second column of Table 3 . In addition to the main effect of bringing one's bag on increasing indulgent purchases, we find evidence of a significant negative interaction effect. Thus having (very young) children does decrease the influence of bringing a bag, in accordance with H3.

\section{Separability of organic and indulgent effects}

We propose that bringing a bag increases organic and indulgent purchases in parallel (e.g. separably, per H4A). However, shoppers could perceive the act of buying organic itself as doing something virtuous. This would suggest a causal chain in which bringing one's bags primes more organic choices, and these organic choices then engage the licensing effects that subsequently increase indulgent choices. We can use the indulgence analysis to test this possibility directly by adding a regressor for the number of organic items in the trip and a regressor for its interaction with the bag variable to equation (4). The results shown in the third column of Table 3 demonstrate a main effect: increases in the number of organic purchases in a trip actually indicate fewer indulgent purchases. However, the interaction effect between bringing bags and the number of organic purchases is not significant, suggesting that their effects are not causally interdependent.

\section{Moderating Effects of Cost Salience}

Since both choosing organic options and buying more indulgences increase consumer spending, it was important to examine whether our main effects were constrained by the salience of these costs (H5). For organic purchases, this is best reflected by higher price premiums. Examining the interaction of the bag with the organic price premium for produce shows a 
significant, negative coefficient, indicating that the increased likelihood of purchasing organic when bringing a bag is indeed reduced by larger price premiums.

In contrast to organic options, indulgences aren't purchased to substitute for a "conventional version" of a category. As a result, to study the impact of cost salience on our effects for indulgences, we need to identify a specific category over which we can compute a price index. To achieve this, we chose ice cream and yogurt, two similar food categories that are perceived to vary in their level of indulgence. To verify the appropriateness of this choice, we examined data from an online survey of 163 people $\left(\mathrm{M}_{\mathrm{Age}}=28.88,53 \mathrm{~F}\right)$ who rated several common grocery store foods on a seven-point indulgence scale. Yogurt was rated below the midpoint of the scale $(\mathrm{M}=3.35, \mathrm{SD}=1.566)$, and was perceived to be significantly less indulgent than ice cream within-subject $(\mathrm{M}=6.43, \mathrm{SD}=.975 ; \mathrm{F}(1,162)=440.98, \mathrm{p}<.001$, repeated measures ANOVA).

Within the store loyalty card data, we calculated a category price index at the daily level based on the weighted per-volume trip prices for each of these categories (as we did with the produce price indices). The mean utility of purchasing in the category is given by:

$$
\mu_{i t} \text { (has category) }=\alpha B_{i t}+\gamma p_{t}+\delta B_{i t} p_{t}+X_{i t} \beta_{i}+\zeta_{h}+\vartheta_{d}+\eta_{w}+\xi_{i} .
$$

We estimate equation (3) using logistic regression and this mean utility expression. The dependent variable is an indicator for whether the trip had a product in the focal category (ice cream or yogurt). The mean utility expression in (5) includes regressors for price and price interacted with the bag dummy. We also included the time since the last purchase in the category as an additional control variable in vector $X_{i t}$. Results from the regressions are shown in Table 4.

Insert Table 4 About Here 
We find that the positive effect of a bag exists only for the ice cream. The absence of an effect in the yogurt category provides a placebo test for our primary hypothesis (H2) and supports our assertion that the set of control variables (vector $X_{i t,}$, household and time dummy variables) appropriately addresses unobserved factors and shopping basket size. Furthermore, the significant negative coefficient on the interaction between price and bringing a bag indicates that as the prices of indulgences increase, the influence of bringing a bag decreases (H5). Overall, our findings indicate that the increased motivation to seek indulgences can be reduced by their costs.

\section{Discussion}

In this analysis of real shopping data, reflecting consumers' normal behavior over the span of several months, we find strong evidence to suggest that bringing one's own grocery bag increases purchases of organic and indulgent foods $(\mathrm{H} 1, \mathrm{H} 2)$. As measured in this sample, these effects are likely to be moderated by whether or not the household includes young dependents (in the case of indulgences), and by the amount of additional spending (or price premium) such purchases require $(\mathrm{H} 3, \mathrm{H} 5)$. We are further able to demonstrate that the effects of bringing one's bag operate in parallel, or are separable, in support of H4A, as the increase in indulgent purchases cannot be explained by the increase in organic choices. All of our effects are robust to the use of linear probability models with standard errors clustered at the household level.

While such results show that these effects are measurable in the noisy setting of the real world, some limitations arise from our inability to directly identify certain variables of interest (e.g. households with children), and/or rule out certain alternate explanations. For example, it is possible that the decision to bring reusable bags, as well as the changes in purchase behavior, are due to an unobserved external condition that occurs with varying frequency. To help address 
these issues and to delve deeper into how observed effects relate to managerial concerns, such as store policies related to bringing one's bags, we carried out the following series of experimental studies.

\section{Study 2: Consumer-Generated Consideration Sets and Household Dependents}

To understand how bringing a bag might influence consumers' self-generated preferences, we designed an open-ended experiment in which participants could list the foods they were most likely to consider buying. In addition, while Study 1 suggests that having young children can attenuate bag effects for indulgent purchases, its findings are bounded by our limited ability to conclusively identify households with dependents. To address H3 more concretely, together with $\mathrm{H} 1$ and H2, we randomly assigned bringing one's own bags in a hypothetical shopping scenario, and created participant categories based on whether or not participants reported having dependents under the age of 18 residing with them.

\section{Methods}

Participants were recruited for this study online from a national pool via Amazon's Mechanical Turk (AMT), and were randomly assigned one of two conditions (With Bags, No Bags). Eleven individuals who did not complete all of the study measures were excluded from the analysis. The remaining sample consisted of 111 participants (ages 18-72, 69 F). Participants indicated their age as one of six ranges (e.g. 18-24, 24-34, etc.), with the median age range as 2434. When asked, thirty-eight participants reported that they had one or more dependents under the age of 18 currently residing in their household. 
The instructions stated that the purpose of the study was to understand supermarketshopping behavior. Participants in the With Bags condition read the following scenario:

Imagine that you are heading into a supermarket to do the grocery shopping for your household for the entire week. Picture yourself walking up towards the door, and selecting a shopping cart from the stand just outside. As you wheel the cart inside, imagine yourself [putting your reusable shopping bags inside the cart and then] looking around the entrance.

In the No Bags condition, participants read an identical passage, with the exception of the bolded clause. Since there is significant variation in the places where an individual might shop (e.g. a corner store vs. a large chain), all participants were shown the same schematic of a grocery store (Figure 2A). This gave everyone in the study the same reference points for the available food categories. Participants were then asked to list the ten items they would be most likely to purchase on this trip. They were directed to be as specific as possible with regards to details such as the numbers, sizes, "types", and brands of the items they listed.

Insert Figure 2 about here

\section{Results}

Our dependent measure was designed to investigate whether bringing one's bags might influence purchasing patterns by increasing the spontaneous consideration or mental accessibility of certain foods. Using the criteria from the empirical analyses, we categorized items as indulgences if they were unambiguously identifiable as having a high fat, high sugar and/or salt content, and fell into two general categories: "desserts" (e.g. candy, ice cream, cakes, cookies) or "chips" (e.g. potato chips, corn chips). For each individual, we summed the total number of indulgent items listed. We then examined the effects of our bag manipulation on the average 
number of indulgences listed for participants who self-reported (not) having dependents under the age of 18 residing in their household.

As indicated in Figure 2B, there were no main effects of bringing one's bag $(\mathrm{F}(1,107)=.760)$ or of having dependents $(\mathrm{F}(1,107)=.940)$. However, there was a significant interaction between these factors $(F(1,107)=4.776 ; \mathrm{p}<.05)$. In particular, participants with dependents did not show an effect of bringing their own bags $(F(1,107)=1.342 ; p=.249)$. In contrast, participants without dependents listed significantly more indulgent items when they envisioned bringing their own shopping bags $(F(1,107)=4.536 ; \mathrm{p}<.05)$. To complete the picture, the differences between the means of the indulgent items for households with and without children in the No Bag condition were not significant $(F(1,107)=2.272 ; p=.135)$. They were similarly not significant between those with and without children for the With Bag condition $(\mathrm{F}(1,107)=2.505 ; \mathrm{p}=.116)$.

Though participants frequently listed items that have organic counterparts, such as milk, they rarely elaborated on whether or not those foods were organic. In fact, only one percent of the items listed across the entire study were labeled as organic or had any potentially relevant environmentally positive designation ("rBST-free", etc.) Thus it was not possible to analyze this data with regards to the effects of bringing bags on organic purchases.

\section{Discussion}

These findings support a combination of $\mathrm{H} 2$ and $\mathrm{H} 3$, because they suggest that bringing one's own bag to the grocery store causes shoppers to increase the number of indulgent foods in their consideration set, or find these foods more mentally accessible, but only if they have no dependents. This is consistent with the conservative analysis performed on the empirical data 
related to indulgent purchases in Study 1. Indeed, examining the regression results in the second column of Table 3 shows that the magnitude of the negative "With Children by With Bags" interaction exceeds the magnitude of the bags' main effect. As such, both studies allow for the possibility that shoppers with dependents show no difference in indulgent purchasing when they bring their own bags. We note that conclusive findings on whether bags exert a main effect or a fully moderated one may depend on use of a larger sample with a more complete representation of household composition (e.g. number of children, ages, and whether or not the children were present during the shopping trip itself.)

The pattern of results raises the interesting possibility that parents' choices are overall less sensitive to aspects of bringing one's bag that relate to the shopper's own benefit (e.g. treating him or herself). Alternately, it may be that individuals with dependents implicitly attribute virtuous behavior like bringing bags to their role as parents and/or to their children, and thus do not feel licensed to indulge. We also found no main effect of having dependents on indulgent purchases. While it is difficult to draw conclusions from a null finding, this may be due to variance in the range of possible goals parents integrate in their shopping (health, children's preferences, environmental concerns, applying a budget across more family members, etc.).

\section{Study 3: Choice Attribution and Price Salience}

In recent years, either by choice or due to new laws, stores have enacted a number of different policies related to shopping bags. These range from simply encouraging adoption of reusable bags to requiring shoppers to bring them. In terms of indulgent purchases, our hypothesized licensing mechanism predicts that consumers should only reward themselves if 
they can attribute the "virtuous act" of bringing a bag to themselves. Thus we examine whether attributing the reason for bringing a bag to the store, rather than the shopper, will indeed reduce the effects of bringing one's bag on indulgent purchases (H4B).

As noted earlier, adding an indulgent product to the basket creates a "novel" or unplanned expense. Since many, if not most, consumers are price sensitive in grocery contexts, the salience of this extra cost might conflict with or deter the effects of bringing one's own bag (e.g. H5). While we found evidence convergent with this hypothesis in a 1-sample comparison of similar indulgent and non-indulgent items in the empirical work, here we aim to strengthen that conclusion for indulgent purchases by varying the salience of costs via the availability of price information.

\section{Methods}

Participants engaged in this study via AMT, and all participants completed all of the survey measures. The very brief nature of the survey, and the non-specific description of indulgences, rendered it difficult to include an explicit attention check query. As a proxy, we excluded the 38 participants who answered the primary dependent variable in less than five seconds after the scenario and question appeared on their screen. The final sample size consisted of $n=428$ individuals who indicated that they did not have dependents under the age of 18 as part of their household $\left(\mathrm{M}_{\mathrm{Age}}=36.1,222 \mathrm{~F}\right)$.

Participants were randomly assigned to one of six conditions in a 3 (No Bag, Self Bag, Store Bag) X 2 (No Price, Price) between-subject design. All participants were asked to imagine that they were headed to the checkout counter of a store after doing their normal grocery shopping, and read one of the following three scenarios: 
No Bag: The checkout person asks if you want paper or plastic bags. You say plastic, and then load your groceries on to the counter.

Self Bag: The checkout person asks if you want paper or plastic bags. You have brought your own reusable bags with you to the store, so you hand those over, and then load your groceries on to the counter.

Store Bag: This store's policy requires customers to bring their own bags, so you have brought reusable bags with you. You hand them over to the checkout person, and then load your groceries on to the counter.

Our aim in this study was to make costs more or less salient in the purchase decision process. Participants in the Price condition read the following: "You also look through the attractive array of chocolates and candy [with prices ranging from 69 cents to \$4] displayed near the register." Participants in the No Price condition saw the same text with the bolded clause removed. This conservative manipulation allowed all participants to draw their own inferences about the additional costs of the items, while offering those in the Price condition a conscious reminder of those costs. To improve the external validity of this design, we encouraged participants to draw from their own preferences and experiences by keeping the parameters of the scenario quite broad (e.g. not specifying the brand/product, and listing a range of prices). All participants then rated how likely they would be to buy one or more of the sweet options on a scale from 1 [Definitely Would Not Buy] to 9 [Definitely Would Buy]. They additionally reported basic demographic and household shopping information.

\section{Results}

Examining the average willingness to purchase a sweet item at the checkout counter revealed no significant main effects of the bag conditions $(F(2,422)=.324 ; p=.723)$ or of price 
information $(\mathrm{F}(1,422)=1.545 ; \mathrm{p}=.215)$. However, as can be seen in Figure 3, there was a significant interaction of the two $(F(2,422)=4.694 ; \mathrm{p}<.02){ }^{8}$

Insert Figure 3 About Here

To address our hypotheses directly, we can break these results down to their simple effects. First, our experiment tests the effects of attributing reusable bags to the store's policy, as opposed to the shopper's own agency. Figure 3 illustrates a marginal trend towards overall differences between the three types of bag conditions when no price information was given $(F(2,422)=2.446 ; p=.088)$. Replicating the first two studies, willingness to purchase indulgences was significantly higher in the Self Bag condition $(\mathrm{M}=4.17, \mathrm{SD}=2.364)$ than in the No Bag condition $(\mathrm{M}=3.34, \mathrm{SD}=2.389 ; \mathrm{p}<.05) .{ }^{9}$ However, there was no such difference due to bringing bags when this process was attributed to the store (Store Bag vs. No Bag: $\mathrm{p}=.427$ ). Interestingly, a similar pattern is found across the three bag conditions in the Price groups $(F(2,422)=2.585$; $\mathrm{p}=.077$ ), though the direction of the effects is different. Specifically, the marginal decrease in willingness to purchase for the Self Bag versus No Bag groups is not present when comparing the Store Bag to the Self Bag condition ( $\mathrm{p}=.757)$. To summarize, bringing one's own bag only impacts the likelihood of purchasing indulgences if the consumers can attribute that action to themselves, consistent with a licensing mechanism (H4B).

We can also ask whether increasing the salience of costs reduces the effects of bringing a bag. In the No Bag condition, intent to purchase indulgences did not differ significantly between the Price or No Price conditions $(F(1,422)=.574 ; \mathrm{p}=.449)$. However, in the Self Bag condition, the presence of price information significantly decreases intent to purchase indulgences compared to No Price $(F(1,422)=10.41 ; \mathrm{p}<.005)$. In line with $\mathrm{H} 5$, we find that when shoppers 
attend to costs in a situation that also focuses on payment (e.g. the checkout register), they eliminate the benefit of bringing one's own bag for indulgent purchases. Indeed, comparing No Bag and Self Bag in the Price condition shows a marginal trend suggesting that when prices are salient, choosing to bring one's own bag might decrease indulgent purchases $(\mathrm{p}=.076)$.

\section{Discussion}

For indulgent items, these results provide evidence that high salience of costs at the time of purchase can interrupt the impact of bringing one's own bag, and potentially even reverse it. This is broadly consistent with our empirical results, which also indicated a moderating effect of increasing prices. However, we note that this experiment conservatively operationalized attention to costs by varying the presence or absence of price. Given the relatively small amount of information provided to participants, this manipulation does differ from a grocery store, in which individual item prices are always present, but often minimized in comparison to product information (e.g. posted on shelf edges and separate from the product). Thus the exact quantitative impact of the interaction between cost salience and bringing one's bags for households without children remains a useful point for future studies.

\section{Study 4: Choice Attribution and the Separability of Organic and Indulgent Effects}

The previous study demonstrated the importance of attribution for only indulgent products. Here, we compare the relative willingness to purchase for both indulgent and organic foods when the choice to bring one's own bags is either attributed to the self or to the store, to examine whether the effects on these two categories are separable (H4A \& B). We predict that 
there should be no differences in the intent to purchase organic items between attribution conditions, given our assumptions about a priming mechanism. In contrast, we predict a decrease in the relative desire to purchase indulgent items when the presence of the bags is attributed to the store.

\section{Methods}

Participants engaged in this study via AMT. One individual who did not complete the survey was excluded from analysis. All participants successfully answered the attention check, in which they were asked to name one grocery item that they had rated during the survey.

Given that the study involved comparing purchase likelihoods for several specific products within-subject (see below), participants were asked to list "dietary preferences (e.g. vegetarian) or restrictions (e.g. gluten-free, lactose intolerant) which influence the items that you buy when you shop." This allowed us to prevent spurious results due to unobserved differences in food restrictions across conditions. Based on their responses, eighteen individuals who indicated constraints/considerations that interacted with the specific items in the study were excluded (Appendix W4), resulting in a sample size of $n=51$ individuals who indicated that they did not have dependents under the age of 18 as part of their household $\left(\mathrm{M}_{\mathrm{Age}}=29.9,15 \mathrm{~F}\right)$.

Participants were asked to imagine themselves engaging in the process of shopping in a grocery store in a scenario similar to that of Study 2. In the "Store" attribution scenario, they were told to imagine the following: "Because this store is requiring people to bring their own bags, you have brought your own reusable bags with you." In the "Self" attribution scenario, they read "You have brought your own grocery bags with you". 
Participants were asked to imagine viewing nine specific products, three from each of the following (a priori defined) categories. "Baseline" products consisted of chicken, canned soup, and lettuce. "Organic" products were organic milk, sustainably farmed organic apples, and cagefree organic eggs. "Indulgent" products were a candy bar, potato chips, and ice cream. The names of the nine products were shown together (simultaneously) on the same page in random order without the explicit category labels. Participants rated their willingness-to-purchase these items on a scale from 1 [Definitely Would Not Buy] to 7 [Definitely Would Buy].

Following this, participants viewed the following description of an indulgent product: “An 'indulgent' product is a treat, or a kind of luxury. Indulgences are pleasurable items that reflect more about what you want than what you need." They then rated each product on a scale from 1 [Not At All Indulgent] to 7 [Very Indulgent]. Finally, participants indicated basic demographic and household shopping information.

\section{Results}

The average perceived indulgence ratings for the items of the baseline, organic, and indulgent categories revealed no between-subjects effect of the attribution of bringing bags $(\mathrm{F}(1,49)=.101 ; \mathrm{p}=.752$, Figure $4 \mathrm{~A})$. Nor was there a significant interaction between attribution and category $(\mathrm{F}(2,98)=1.730 ; \mathrm{p}=.183)$. Thus participants across the two conditions had similar perceptions of how indulgent the different foods were. As expected, there were significant differences among the three categories of foodstuffs within-subject $(F(2,98)=386.9 ; p<.001)$. Direct contrasts showed that organic foods were considered somewhat more indulgent than the baseline items $(\mathrm{p}<.005)$. Indulgent products received the highest rating, and were considered significantly more indulgent than organic $(\mathrm{p}<.001)$ and baseline foods $(\mathrm{p}<.001)$. 
Insert Figure 4 about here

It is not sufficient to measure changes in willingness-to-purchase for individual organic or indulgent products, since the attribution manipulations could have had main effects on overall willingness to buy groceries. Thus our baseline category offered us a common reference point, or control, for each individual, similar to the within-household comparisons used in Study 1's empirical analyses.

We calculated difference measures between the average willingness to purchase for indulgences vs. baseline items, and organic foods vs. baseline items. We then compared this difference score between the Store and Self conditions to see whether the effects of the bags on organic and indulgent purchases could be separated merely by changing the attribution (Figure 4B). As noted above, frequent weekly grocery purchases were selected as baseline products. Aligning with this, participants in both attribution conditions were more willing to purchase the baseline items than the other items. This resulted in net negative difference scores for both indulgent and organic categories.

Participants in the Self group were more willing to purchase indulgent foods, compared to baseline $\left(M_{\text {Self }}=-1.04, S D=1.24\right)$, than participants in the Store group $\left(M_{\text {Store }}=-1.96, S D=1.64\right.$; $F(1,49)=4.891 ; p<.05)$. However, though the Store participants showed a relative attenuation of indulgent purchases, they showed no significant difference from Self participants for organic purchases $\left(\mathrm{M}_{\text {Store }}=-1.00, \mathrm{SD}=1.91 ; \mathrm{M}_{\text {Self }}=-1.51, \mathrm{SD}=1.55 ; \mathrm{F}(1,49)=1.048 ; \mathrm{p}=.311\right)$. The interaction between these two effects was significant $(F(1,49)=5.933 ; p<.02)$, demonstrating that the effects of attribution were indeed distinct for indulgent and organic categories. ${ }^{10}$ Overall, our 
findings support H4A\&B as a pair, and show that bringing one's bags influences organic and indulgent purchases through separable pathways that can be differentiated by attribution.

\section{General Discussion}

Efforts to combat climate change and address environmental issues have gained prominence across the United States and on the global stage. One target of these efforts has been to curb the use of plastic grocery bags by encouraging shoppers to bring their own bags. Here, we study some of the effects of adopting that behavior on purchasing patterns. In an empirical analysis of data from a large sample of shoppers taken over several months, we find that bringing bags can encourage purchases of similarly environmentally conscious organic items. We also find that this action can spur increased purchases of indulgent foods, such as desserts, candy, and snack chips.

Considering our experimental and empirical findings together further nuances these main results and helps demonstrate that they are constrained by several common factors, which are of relevance to both consumers and retailers. For example, shoppers only seem to "treat themselves" to indulgences when they can comfortably take credit for having brought their own bags; when bringing bags can be attributed to store policy, their influence is reduced. In addition, effects on indulgent foods can be crowded out or complicated when shoppers' purchasing priorities include the needs and wants of others, such as young dependents. For both organic and indulgent purchases, the bags' effects are also attenuated by the salience of costs.

The bag-related increase in purchase of organic produce is notable in that it is observed in empirical tests of repeat trips across the same households. This suggests that our results are not 
simply due to some shoppers having a higher tendency to buy organic than others. Exploratory analyses of our data examining a broad range of foods with organic and non-organic options suggest that these effects carry across several categories. Given the degree to which individuals identify organic foods as both morally virtuous (Mazar and Zhong 2010; Eskine 2013) and environmentally beneficial (Yiridoe et al. 2005; Hughner et al. 2007; Shafie and Rennie, 2012), we would further expect this finding to extend to environmentally friendly product domains outside food, such as cleaning or paper supplies.

The relationship of reusable bags and organic food might appear somewhat intuitive. Though the increase in indulgent purchases is less obvious, it is consistent with previous research on the licensing effect, in which making a virtuous choice in one domain allowed individuals to indulge on a later choice (Khan and Dhar 2006). There are several reasons why the act of bringing a bag can be virtuous, making this a viable mechanism for our effects: environmental benefits, potential social approval of the action, and even the positive reinforcement provided by the stores themselves. As such, by demonstrating these effects in an externally valid context, our findings extend our theoretical and practical understanding of the scope within which licensing can operate. In addition, while earlier studies consisted of entirely unrelated decisions with forced-choice tradeoffs between virtues and vices, we find licensing with open-ended decisions that are consciously a part of the same overall shopping event.

We note that in Study 4, organic products were considered somewhat more indulgent than conventional products, raising the question of whether bringing a bag might increase organic purchases through licensing, in addition to priming. While we cannot directly rule this out, the findings in Study 4 also demonstrate that the effects of bringing a bag are not influenced by whether that choice is attributed to the consumers themselves or to store policy. Since self- 
attribution for the virtuous action is a central element of licensing (Khan and Dhar 2006), it is much less likely that this mechanism underlies our organic purchase results.

Beyond concerns for the environment, organic foods can be selected for more personal health-conscious reasons (e.g. Yiridoe et al. 2005). Health (and diet) concerns can shift the way that shoppers approach indulgences, and/or influence their perceptions of which categories constitute indulgences. To understand their implications for the effects of bringing one's bags, it will be necessary for future studies to examine these types of interactions more directly.

This idea of competing goals raises the question of whether our results apply equally across different kinds of households. As noted, shoppers with young dependents may have dominant criteria, goals, or demands that redirect their choices (Thompson and Kidwell 1998; Mangleburg 1990; Hill and Lynchehaun, 2002; Prasad et al., 2008), including consideration of the children's preferences (Marshall et al. 2007; Martensen and Gronholdt 2008). While we are able to show evidence that having children moderates the effects of bringing a bag for indulgences in both Studies 1 and 2, we do not observe such an interaction for organic food. This provides further evidence that the effects on organic and indulgent purchases are occurring in parallel, and points to an interesting distinction between priming as a memory-based mechanism, and licensing as a self-perception-based mechanism. Overall, household composition remains a useful area for additional research, particularly in terms of informing the targeting of promotional materials, and with regards to products the children themselves might consume.

The salience of costs offers a second factor competing with our effects, as evidenced by Studies 1 and 3. In Study 3, reminding individuals of the items' financial costs appeared to eliminate or even reverse the effect of the bag manipulation in the "Self" condition. It may be that high salience of costs evoked savings goals, causing participants to actively avoid spending. 
Alternately, since shoppers may have already accounted for basket costs at the register, the impact of considering additional spending at this location may be particularly high. We note that these factors may not sufficiently predict why high salience of price should cause shoppers who brought their own bags to decrease consideration of indulgent purchases.

A more nuanced picture of cost salience arises from Study 1, in which purchasing was sensitive to the level of price, with higher prices reducing the effects of bringing a bag. Thus awareness of costs may simply reduce consumer surplus by increasing pain-of-paying (e.g. Prelec and Loewenstein, 1998, Thomas et al. 2011). Another consideration is that stores often draw attention to prices when they reflect promotional discounts or reductions in costs, which might actually be expected to increase indulgent purchases (Khan and Dhar 2010). Thus the interaction of these effects with the framing of price information offers several opportunities for additional research.

Overall, our studies indicate that the single act of bringing one's bags can increase purchases of organic and indulgent foods in parallel by separable mechanisms. The results of Study 1 suggest that these two effects could occur simultaneously. Indeed, the multi-choice nature of grocery store shopping offers different channels for these effects to be expressed without obvious conflict. However, on this point our current experimental data is not conclusive. While we show that these effects can coexist, further study is necessary to understand the balance of their expression for any particular shopper.

\section{Managerial Implications}


In our grocery store data, the average premium paid for organic produce is $\$ 0.195$, or $8.75 \%$. We use the estimated coefficients from our regression results in column 1 of Table 2 to calculate fitted utility values of purchasing organic produce both with and without a bag, using equation (2). We then use equation (3) to calculate the probabilities of purchasing organic produce for every shopping trip in the data, both if the consumer brought and did not bring a bag. On average, we find that bringing a bag increases the probability of purchasing organic produce by $13.3 \%$, from $5.95 \%$ to $6.74 \%$. On the average shopping trip, consumers spend $\$ 47.47$. Assuming that this effect results from substituting organic produce for non-organic produce, this is a revenue increase of $\$ 0.00154(0.00325 \%)$ per trip. Under the alternative assumption that these are additional purchases, using the average organic produce price of $\$ 2.42$ the revenue increase is $\$ 0.0191(0.0403 \%)$ per trip.

Indulgent items can also increase the store's revenue. Using the estimated coefficients from column 1 of Table 3, we calculate that the average increased probability of purchasing an indulgent item due to bringing a bag is $7.26 \%$, from $17.9 \%$ to $19.2 \%$. Under the assumption that indulgent items are additional unplanned purchases, and the additional conservative assumption that the indulgent items cost $\$ 2.00$ on average, this implies an average increase of $\$ 0.0260$ $(0.0548 \%)$ in shopping basket expenditure per trip.

The combined effect assuming increased purchases for both types of products suggests a $0.0951 \%$ increase in spending on one purchase occasion due to the causal impacts of bringing one's bag. While this number does not appear large, given the size of the $\$ 550$ billion grocery industry, its overall impact can be substantial. With these figures, we can compute the revenue gains (and profit gains, assuming a common proportional markup) from increasing the probability that consumers bring bags. Under a hypothetical policy that would double the share 
of trips with bags from 1.62 percent to 3.24 percent, there would be a revenue increase of $\$ 8.47$ million dollars (assuming similar numbers industry wide). However, once bringing a bag becomes more habitual to shoppers, or required by external regulation, its psychological impact may decrease, causing such effects to decline in magnitude.

Currently, many stores encourage the practice of carrying reusable bags by providing such bags for purchase, giving bags away, or offering minor financial credits, all of which encourage the consumer to actively choose to "be green." In contrast, policies that require customers to bring bags generally take the form of punishment by charging for bags from the store. Studies 3 and 4 indicate that the influence of bringing one's bags on indulgent purchases is likely to be stronger under encouragement than punishment. Overall, policies that emphasize the environmental and/or social benefits of the bags, and the shopper's agency in choosing to use them, are likely to have the strongest impact on behavior in both organic and indulgent domains.

Our results offer ways of encouraging green decisions, as well as decisions with potential health benefits. In stores where adoption of reusable bags is growing, promoting offerings like organic or sustainably farmed foods as indulgences could increase their purchase rates. Furthermore, consumers might be more willing to consider environmentally friendly brands of indulgent non-food products if emphasis is placed on their indulgent qualities.

Finally, our findings suggest that the well-used mantra of "location, location, location" still has a lot to offer to retailers. For example, Hui, Bradlow and Fader (2009) find that licensing-type effects significantly influence grocery store choices in a way that actually changes shopping paths. Since many grocery stores have their fresh produce sections near the entryway, highlighting organic offerings early on could entice individuals primed by bringing their own bags to further explore these sections, and/or increase organic or healthful choices initially. Our 
results further suggest that in-store messaging related to the shopper having made these virtuous choices might then aid consideration of subsequently encountered indulgent choices.

Another location-based element of interest is the checkout register, where shoppers are reminded of the presence (or absence) of bags brought from home. At this time, shoppers are also exposed to relatively low-cost "impulse" or unplanned items. Study 3 shows that bringing a bag can boost indulgent purchases at this location, and predicts that consumers might also be open to considering relatively inexpensive environmentally positive products. Overall, these findings have important implications in terms of product offerings, the positioning of such offerings in stores, and the potential for engaging in environmental promotional activity overall.

\section{Concluding Remarks}

We demonstrate how taking an environmentally friendly action can influence subsequent choices in actual grocery shopping behavior and in controlled experimental studies, providing results of managerial importance. The work contributes to the literature by demonstrating downstream priming and licensing effects of a choice that can arise from social, moral, and/or political motivations. We show that these effects can occur in a highly complex "real world" choice environment, one in which consumers are targeted by a vast quantity of marketing messages and are likely to be driven by a number of motivations. We also explore how our effects are constrained by realistic competing factors such as household dependents and costs. As a whole, our findings show that shoppers who bring their own bags are generally more likely to treat the environment, but they treat themselves most when situational factors help them feel more deserving and less guilty about doing so. 


\section{References}

Bargh, John A., Annette Lee-Chai, Kimberly Barndollar, Peter M. Gollwitzer, and Roman Trötschel. (2001) "The automated will: Nonconscious activation and pursuit of behavioral goals." Journal of personality and social psychology 81, no. 6: 1014.

Chappell, Bill. (2014, Sept 30) “Ban On Single-Use Plastic Bags Is Enacted In California” NPR (The Two-Way: Breaking News from NPR). Retrieved from http://www.npr.org

Dijksterhuis, Ap, Pamela K. Smith, Rick B. Van Baaren, \& Daniel L.H. Wigboldus. (2005). The unconscious consumer: Effects of environment on consumer behavior. Journal of Consumer Psychology, 15(3), 193-202.

Eskine, Kendall J. (2013) Wholesome Foods and Wholesome Morals? Organic Foods Reduce Prosocial Behavior and Harshen Moral Judgments. Social Psychology and Personality Science, 4(2): 251-4.

Fishbach, Ayelet and Ravi Dhar (2005), "Goals as Excuses or Guides: The Liberating Effect of Perceived Goal Progress on Choice," Journal of Consumer Research, 32 (3), 370-77.

Food Shopper Insights (2011) in Chapter 4 In the Store: The Topline, p. 63 Accessed from MarketResearch.com, 4/9/12. 
Galbraith, Kate. (2012, February 8) “Should Plastic Bags Be Banned?” New York Times. Retrieved from www.nytimes.com.

Hill, Helene, and Fidelma Lynchehaun. (2002) "Organic milk: attitudes and consumption patterns." British Food Journal 104.7: 526-542.

Hughner, Renée Shaw, Pierre McDonagh, Andrea Prothero, Clifford J. Shultz, and Julie Stanton. (2007) "Who are organic food consumers? A compilation and review of why people purchase organic food." Journal of Consumer Behaviour 6(2): 94-110.

Hui, Sam K., Eric T. Bradlow, and Peter S. Fader. (2009) "Testing behavioral hypotheses using an integrated model of grocery store shopping path and purchase behavior." Journal of Consumer Research 3(3): 478-493.

Katz, Ethan. (2001) "Bias in Conditional and Unconditional Fixed Effects Logit Estimation." Political Analysis 9(4): 379-384

Khan, Uzma, and Ravi Dhar. (2006) "Licensing effect in consumer choice." Journal of Marketing Research: 259-266.

Khan, Uzma, and Ravi Dhar. (2010) "Price framing effects on the purchase of hedonic and utilitarian bundles." Journal of Marketing Research: 1090-1099. 
Kivetz, Ran, and Itamar Simonson. (2002) "Earning the right to indulge: Effort as a determinant of customer preferences toward frequency program rewards." Journal of Marketing Research 39.2: $155-170$.

Mangleburg, Tamara F. (1990) "Children's influence in purchase decisions: a review and critique." Advances in Consumer Research 17.1: 813-825.

Mazar, Nina, and Chen-Bo Zhong. (2010) "Do green products make us better people?" Psychological Science 21.4: 494-498.

Marshall, David, Stephanie O'Donohoe, and Stephen Kline. (2007) "Families, food, and pester power: beyond the blame game?" Journal of Consumer Behaviour 6.4: 164-181.

Martensen, Anne, and L. Gronholdt. (2008) "Children's influence on family decision making." Innovative Marketing 4.4: 14-22.

O'Donnell, Jayne (2010, January 29). "Retailers try new survival strategies for 2010". USA Today. Retrieved from www.usatoday.com/money.

Park, C. Whan, Easwer S. Iyer, and Daniel C. Smith (1989), "The Effects of Situational Factors on In-Store Grocery Shopping Behavior: The Role of Store Environment and Time Available for Shopping,” Journal of Consumer Research, 15 (March), 422-433. 
Prasad, Ashutosh, Andrei Strijnev, and Qin Zhang. (2008) "What can grocery basket data tell us about health consciousness?." International Journal of Research in Marketing 25.4: 301-309.

Okada, Erica Mina. "Justification effects on consumer choice of hedonic and utilitarian goods." Journal of Marketing Research 42.1 (2005): 43-53.

Prelec, Drazen and George Loewenstein (1998), “The Red and the Black: Mental Accounting of Savings and Debt," Marketing Science, 17 (1), 4-28.

Schacter, Daniel L. and Randy L. Buckner. (1998) "Priming and the brain. Review." Neuron 20: 185-195.

Shafie, Farah A. and Denise Rennie. (2012) “Consumer Perceptions towards Organic Food." Procedia - Social and Behavioral Sciences 49: 360-367.

Shah, James Y. (2005) "The automatic pursuit and management of goals." Current Directions in Psychological Science 14.1: 10-13.

Smith, Michelle R. (2007, Sept 16) "Retailers push reusable bags to save money, environment. “Associated Press/USA Today/ABC News. Retrieved from http://abcnews.go.com

Stern, Irena C. (2007, August 5), “Greening up by Cutting Down on Plastic Bags,” New York Times. Retrieved from http://www.nytimes.com. 
Thomas, Manoj, Kalpesh Kaushik Desai, and Satheeshkumar Seenivasan. (2011) "How credit card payments increase unhealthy food purchases: Visceral regulation of vices." Journal of Consumer Research 38.1: 126-139.

Wang, Wenbo. (2013) “Green Lifestyle Adoption: Shopping without Plastic Bags.” Working Paper

Wheeler, S. Christian, and Kenneth G. DeMarree. (2009) "Multiple Mechanisms of Prime-toBehavior Effects." Social and Personality Psychology Compass 3.4: 566-581.

Yiridoe, Emmanuel K., Samuel Bonti-Ankomah, and Ralph C. Martin. (2005) "Comparison of consumer perceptions and preference toward organic versus conventionally produced foods: a review and update of the literature." Renewable Agriculture and Food Systems 20.04: 193-205. 


\section{Footnotes}

1. The data provided by the firm was organized at the household-trip-product level, i.e. each observation was a purchased product that included both a shopper ID and a trip ID. This allowed us to calculate variables that describe the composition of products within consumers' shopping baskets.

2. We also exclude trips in which the shopper purchased over a hundred items, trips that were the second visit of the day, and "households" that made more than 660 trips during the approximately two year span of the data (since these were likely to be small businesses).

3. Our results are robust to different definitions of the category (i.e. to making the category more or less broadly inclusive).

4. Our specification only allows us to determine the presence of very young children in the household; those in the "Without Children" condition may in fact have older dependents. However, since we hypothesize that having children diminishes our effects, this analysis acts as a more conservative test.

5. We thank the editor for suggesting this random utility specification.

6. We used an unconditional Logit model, since the conditional Logit model is intractable with the number of shopping trips we observe per household. Katz (2001) has shown that with at least 15 observations per household, the asymptotic bias present in the unconditional Logit is negligible.

7. As before, we verify robustness of this result using the random effects Logit model.

8. This interaction remains significant when including individuals who responded in less than five seconds $(\mathrm{F}(2,465)=3.316, \mathrm{p}<.04)$. Across this experiment, none of the nonsignificant results achieved significance in this unrestricted sample.

9. This effect is reduced to a marginal trend in the unrestricted version of the sample $(\mathrm{p}=.087)$.

10. Conducting these analyses on a sample that included the 18 individuals with dietary restrictions yielded results that followed a similar pattern, but did not reach significance in the interaction between purchase category and attribution $(F(1,67)=2.351, p=.130)$, or in the simple effects contrast between willingness to purchase indulgences for Store vs. Self attribution $(F(1.67)=2.697 ; p=.105)$. 
TABLE 1

Trip-level summary statistics

\begin{tabular}{l|c|c|c} 
Variable & Mean & Std. Dev. & $\mathbf{N}$ \\
\hline Expenditure (gross, \$) & $\$ 47.365$ & $\$ 49.898$ & 142,380 \\
\hline Number of items & 14.094 & 14.178 & 142,380 \\
\hline Days since last trip & 4.039 & 8.337 & 142,380 \\
\hline Txn has bag & 0.100 & 0.300 & 142,380 \\
\hline Txn has produce & 0.631 & 0.483 & 142,380 \\
\hline Txn has organic produce & 0.056 & 0.231 & 142,380 \\
\hline Txn has baby item & 0.062 & 0.242 & 142,380 \\
\hline Txn has yogurt & 0.047 & 0.211 & 142,380 \\
\hline Txn has candy & 0.047 & 0.211 & 142,380 \\
\hline Txn has cookies & 0.101 & 0.302 & 142,380 \\
\hline Txn has chips & 0.085 & 0.278 & 142,380 \\
\hline Txn has ice-cream & 0.030 & 0.171 & 142,380 \\
\hline $\begin{array}{l}\text { Txn has candy, cookies, chips, or ice- } \\
\text { rream }\end{array}$ & 0.187 & 0.390 & 142,380 \\
\hline Price non-organic produce (\$) & 2.228 & 0.121 & 141,862 \\
\hline Price organic produce (\$) & 2.424 & 0.268 & 141,862 \\
\hline Organic produce price premium (\$) & 0.195 & 0.264 & 141,862 \\
\hline Price yogurt (\$) & 1.254 & 0.152 & 134,477 \\
\hline Price ice-cream (\$) & 3.820 & 0.175 & 138,710 \\
\hline & & & \\
\hline & & & \\
\hline
\end{tabular}


TABLE 2

\section{Logit regressions for organic purchases}

\begin{tabular}{l|c|c|c}
\multicolumn{1}{c|}{ DV: Item is organic } & No moderation & $\begin{array}{c}\text { Children as } \\
\text { moderator }\end{array}$ & $\begin{array}{c}\text { Price as } \\
\text { moderator }\end{array}$ \\
\hline Bag & $0.164^{* * *}$ & $0.142^{*}$ & $0.225^{* * *}$ \\
& $(0.042)$ & $(0.058)$ & $(0.049)$ \\
Has children & & 0.889 & \\
& & $(0.723)$ & \\
Bag X has children & 0.066 & \\
& & $(0.108)$ & \\
Organic price premium $(\$)$ & $-0.133^{* * *}$ & $-0.245^{*}$ & -0.081 \\
& $(0.075)$ & $(0.075)$ & $(0.075)$ \\
Has children X Organic & & $0.293^{*}$ & \\
price premium $(\$)$ & & $(0.124)$ & \\
Bag X Organic Price & & & $-0.334 *$ \\
premium $(\$)$ & & & $(0.136)$ \\
& & 96,959 & 132,316 \\
\hline N & 132,316 & $-16,104$ & $-22,312$ \\
\hline Log-Likelihood & $-22,315$ & & \\
\hline
\end{tabular}

Standard Errors in Parentheses. .*** 0.1\% significance, $* * 1 \%$ significance, $* 5 \%$ significance. Control variables include dummies for household, time-of-day, day-or-week, and week-in-data... 
TABLE 3

\section{Logit regression results for indulgent purchases}

\begin{tabular}{l|c|c|c|} 
DV: Txn has indulgent & No moderation & $\begin{array}{c}\text { Children as } \\
\text { moderator }\end{array}$ & $\begin{array}{c}\text { Organic items as } \\
\text { moderator }\end{array}$ \\
\hline Bag & $0.104 * * *$ & $0.118^{* * *}$ & $0.101^{* * *}$ \\
\# organic & $(0.028)$ & $(0.036)$ & $-0.030)$ \\
Bag x \# organic & & & $(0.009)$ \\
& & & 0.006 \\
Has children & & $-1.178^{* *}$ & $(0.017)$ \\
Bag x has children & & $(0.385)$ & \\
Days since last txn (10s) & & $-0.146 *$ & $(0.073)$ \\
Days since last txn squared & -0.017 & 0.000 & -0.016 \\
& $(0.028)$ & $(0.031)$ & $(0.028)$ \\
\hline N & 0.001 & -0.001 & 0.001 \\
\hline Log-likelihood & $(0.003)$ & $(0.003)$ & $(0.003)$ \\
\hline
\end{tabular}

Standard Errors in Parentheses. . *** 0.1\% significance, ** 1\% significance, * 5\% significance. Control variables include dummies for household, number of non-indulgent items purchased, time-of-day, day-or-week, and week-indata. 
TABLE 4

Logit regressions testing the effects of cost on indulgent purchase effects

\begin{tabular}{l|c|c} 
DV: Txn has ice cream & Ice-cream & Yogurt \\
\hline Bag & $1.309^{*}$ & 0.221 \\
price (\$) & $(0.632)$ & $(0.243)$ \\
& -0.010 & $-0.025^{*}$ \\
Bag x price & $(0.008)$ & $(0.010)$ \\
& $-0.032^{*}$ & -0.012 \\
Days since last txn (10s) & $(0.017)$ & $(0.019)$ \\
& 0.047 & $0.382^{* * *}$ \\
Days since last txn squared & $(3.622)$ & $(0.036)$ \\
& -0.006 & $-0.0359^{* * *}$ \\
Days since last purchase in & $(0.004)$ & $(0.004)$ \\
category (10s) & $0.023^{* * *}$ & $0.014^{* * *}$ \\
\hline $\mathrm{N}$ & $(0.002)$ & $(0.003)$ \\
\hline Log-likelihood & 126,844 & 118,226 \\
\hline
\end{tabular}

Standard Errors in Parentheses. . *** 0.1\% significance, $* * 1 \%$ significance, $* 5 \%$ significance. Control variables include dummies for household, number of non-indulgent items purchased, time-of-day, day-or-week, and week-indata. 
FIGURE 1

Histogram of trip purchase times (Hour $0=$ the first hour of the day.)

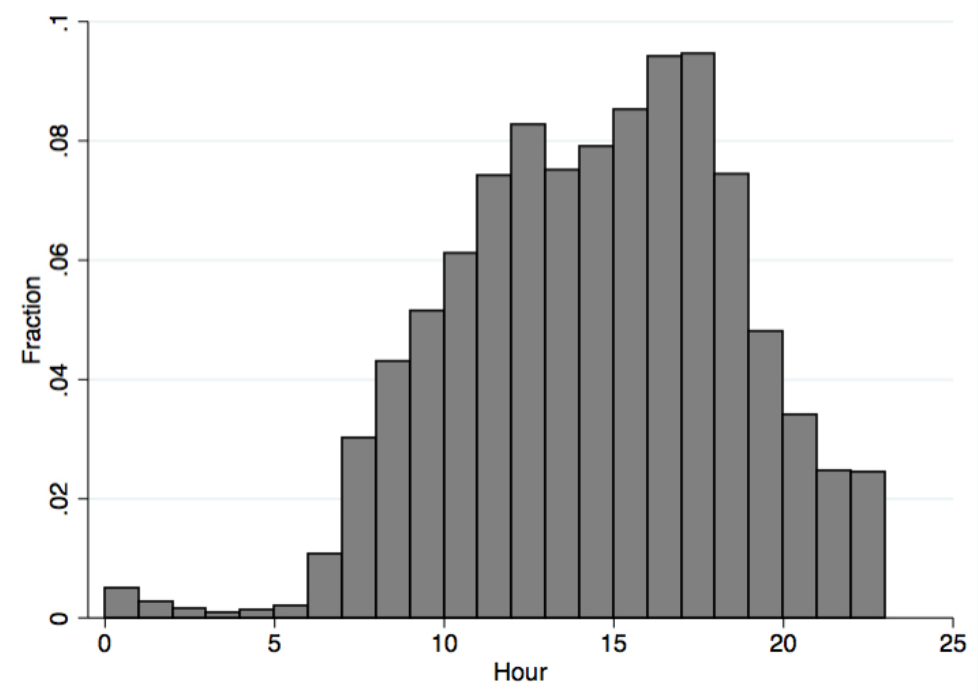


FIGURE 2

Study 2 design and results A) Grocery store layout viewed by all participants. B) Number of indulgent items listed across conditions. Reference bars reflect S.E.

A.
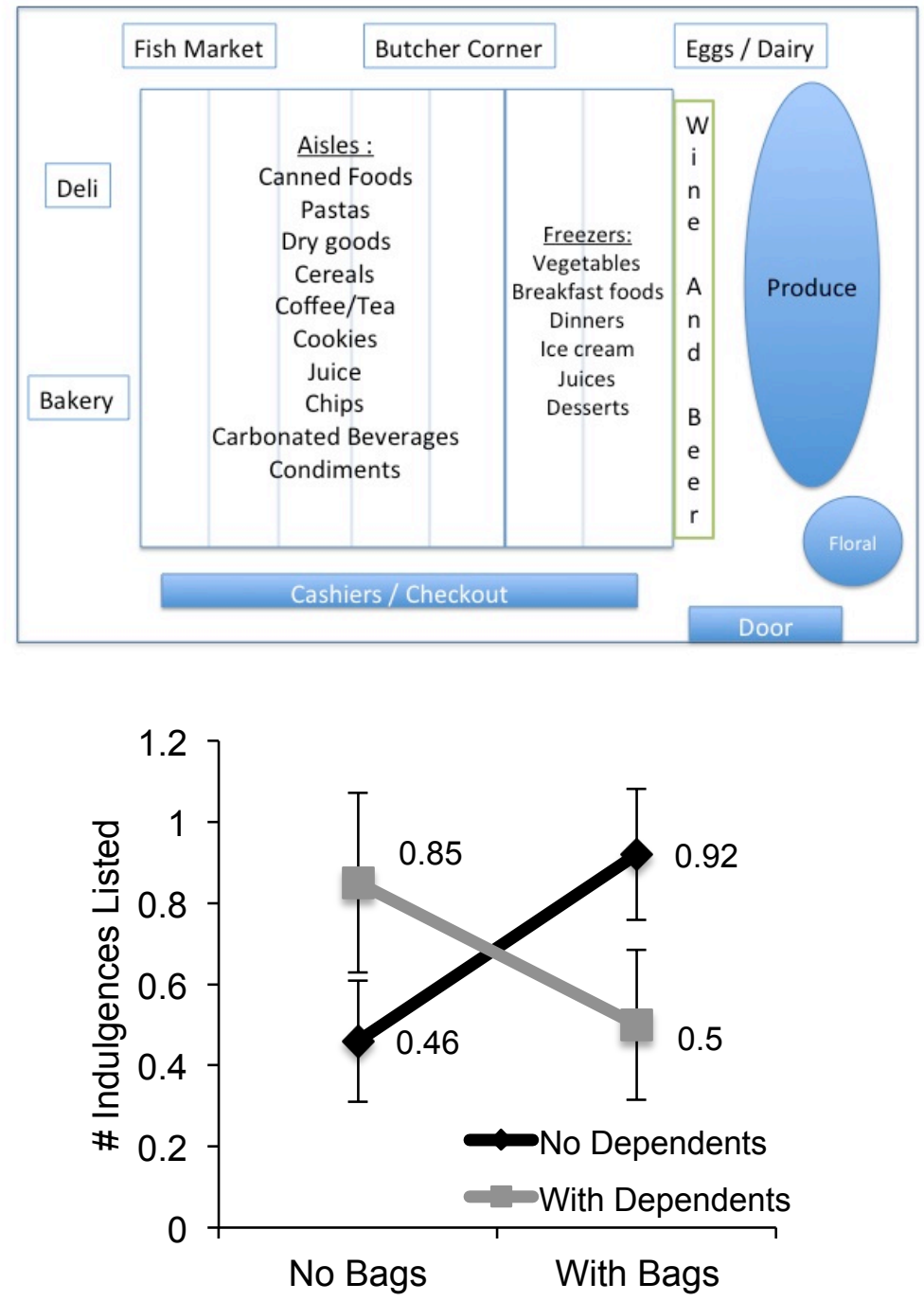
FIGURE 3

Study 3, Willingness to purchase sweet "treats" at the checkout counter, shown by bag condition and availability of price information.

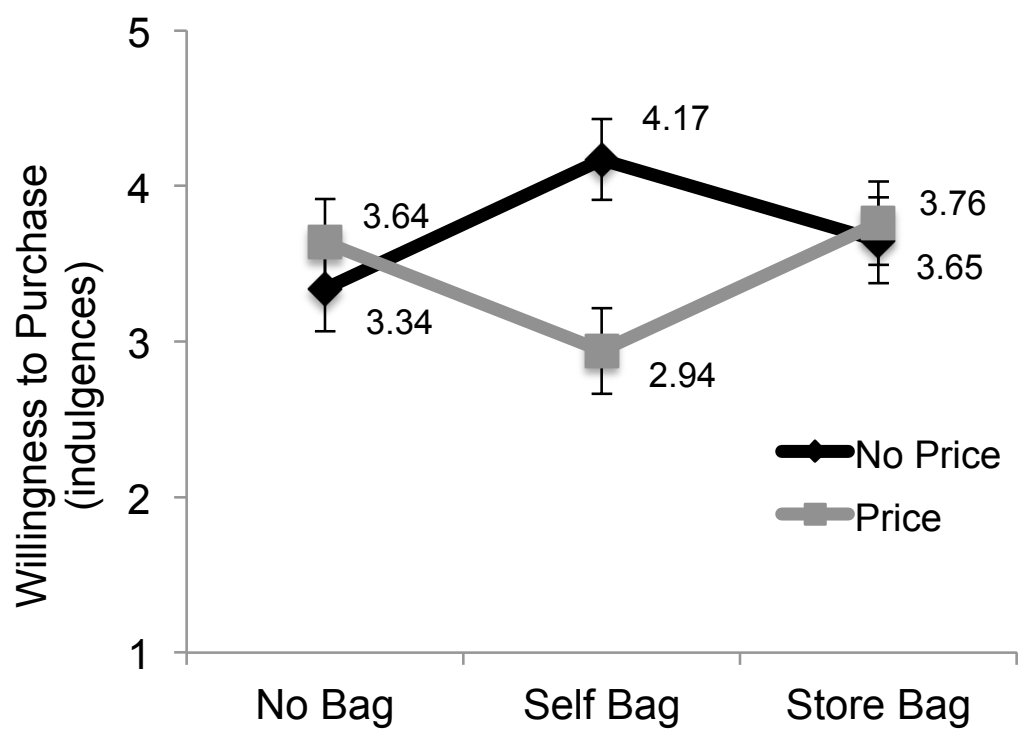




\section{FIGURE 4}

Study 4 results. A) Indulgence ratings for the 3 grocery categories. B) Willingness-to-purchase for indulgent and organic foods (with baseline subtracted), shown by attribution condition. Reference bars reflect S.E.

A.

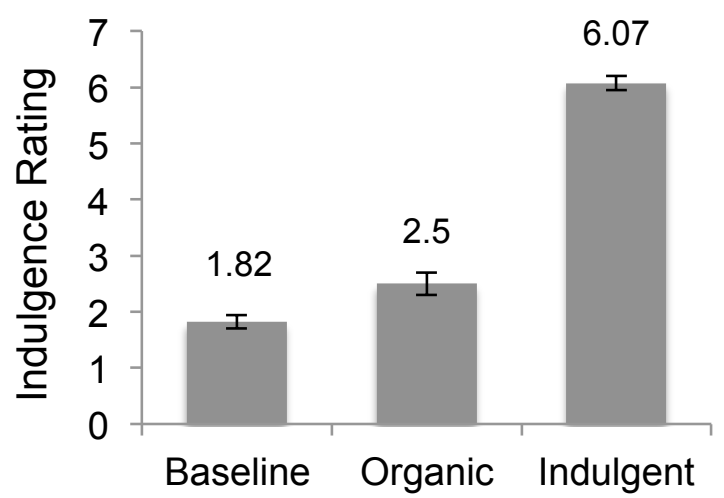

B.

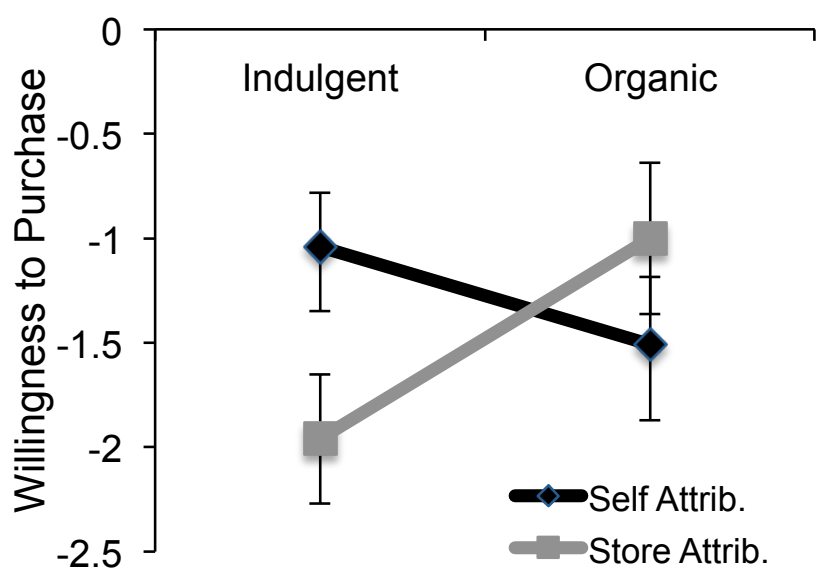




\section{APPENDIX W1}

Complete list of "baby categories" used to define households with young dependents in Study 1.

APPAREL BABY ACCESSORIES

BABY ACCESSORIES, CUPS

BABY BATH INFANT TOILETRIES

BABY LOTION INFANT TOILETRIES

BABY LOTION/CREAM INFANT

TOILETRIES

BABY OIL INFANT TOILETRIES

BABY POWDER INFANT TOILETRIES

BABY SHAMPOO INFANT TOILETRIES

BABY WIPES MAINSTREAM

BABY WIPES SUPER PREMIUM

BABY WIPES VALUE/ECONOMOY

BABY/YOUTH PREMIUM WIPES

BEDWETTERS (HUGGIES GOODNITES,

SFWY EAS

BIBS BABY CLOTHING BABY CARE

BOWLS, PLATES \& SETS FEEDING

ACCESSORIE

COWS MILK BASED INFANT FORMULA

CUPS FEEDING ACCESSORIES BABY

CARE

DIAPER ACCESSORIES

DIAPER RASH INFANT TOILETRIES

DIAPER RASH/PROTECTIVE OINTMENTS

DISPOSABLE BOTTLES NURSING

SUPPLIES

FEEDING ACCESSORIES BABY CARE

FIRST FOODS BABY FOOD

FOOD SUPPLEMENTS (PEDIASURE)

INFANT BABY JUICE

INFANT BAKERY

INFANT CEREAL BABY FOOD

INFANT SOCKS CLOTHING BABY CARE

KIDS/TODDLERS INFANT TOILETRIES

LARGE (34+LB) DISPOSIBLE SWIM PANTS

MAINSTREAM BABY/YOUTH WIPES

MAINSTREAM DISPOSABLE DAIPERS

MAINSTREAM FIRST FOODS BABY FOOD

MAINSTREAM INFANT BABY JUICE

MAINSTREAM INFANT CEREAL

MAINSTREAM SECOND FOODS BABY

FOOD

MAINSTREAM THIRD FOODS BABY FO

MAINSTREAM THIRD FOODS BABY FOOD
MAINSTREAM TODDLER FOOD

MAINSTREAM TODDLER JUICE

MAINSTREAM TRAINING PANTS

DISPOSABLE

MAINSTREAM YOUTH PANTS

DISPOSABLE

MANUFACTURER/WIC INFANT FORMULA

MEDIUM (24-33LB) DISPOSIBLE SWIM

PANTS

MISC

MISC BABY/YOUTH WIPES

MISC DISPOSABLE DIAPERS

MISCELLANEOUS CLOTHING BABY

CARE

MISCELLANEOUS FEEDING

ACCESSORIES BABY

MISCELLANEOUS NURSING SUPPLIES

MISCELLANEOUS TOILETRIES

NURSING PADS NURSING SUPPLIES

NURSING SUPPLIES

ORAL ELECTROLYTES/WATER

PACIFIER ACCESSORIES BABY CARE

PACIFIERS

PACIFIERS BABY CARE

PREMIUM DISPOSABLE DIAPERS

PREMIUM INFANT BABY JUICE

PREMIUM INFANT CEREAL BABY FOOD

PREMIUM SECOND FOODS BABY FOOD

PREMIUM THIRD FOODS BABY FOOD

REFILLABLE BOTTLES NURSING SUP

REFILLABLE BOTTLES NURSING

SUPPLIES

SAFETY BABY ACCESSORIES

SECOND FOODS BABY FOOD

SMALL (16-26LB) DISPOSIBLE SWIM

PANTS

SOLID TEETHERS BABY CARE

SOLUTION FOR SPECIAL NEEDS INFANT TOILE

SOY BASED INFANT FORMULA

SPECIALTY INFANT FORMULA

SUPER PREMIUM DISPOSABLE DIAPE

SUPER PREMIUM DISPOSABLE DIAPERS

SWIM PANTS (HUGGIES SWIMMERS) 


\author{
TEETHERS \\ THIRD FOODS BABY FOOD \\ TODDLER BAKERY \\ TODDLER CEREAL \\ TODDLER FOOD \\ TODDLER JUICE \\ TOYS BABY \\ TRAINING PANTS DISPOSABLE \\ UA-BABY ACCESSORIES \\ UA-BABY FOOD \\ UA-BABY/YOUTH WIPES \\ UA-CLOTH DIAPERS/LINERS \\ UA-CLOTHING BABY CARE \\ UA-DIAPER ACCESSORIES BABY CARE \\ UA-DISPOSABLE DIAPERS \\ UA-DISPOSABLE PANTS \\ UA-DISPOSABLE PANTS (TRAINING \\ PANTS/YOU \\ UA-DISPOSABLE SWIM PANTS DAIPERS \\ UA-DISPOSABLE SWIM PANTS DIAPERS \\ UA-FEEDING ACCESSORIES BABY CARE \\ UA-FIRST FOODS BABY FOOD \\ UA-INFANT BABY JUICE \\ UA-INFANT BAKERY BABY FOOD \\ UA-INFANT CEREAL BABY FOOD
}

UA-INFANT FORMULA

UA-INFANT TOILETRIES

UA-MISCELLANEOUS BABY CARE

UA-NURSING SUPPLIES

UA-PACIFIERS AND ACCESSORIES BABY

CARE

UA-SAFETY BABY CARE

UA-SECOND FOODS BABY FOOD

UA-TEETHERS BABY CARE

UA-THIRD FOODS BABY FOOD

UA-TODDLER BAKERY BABY FOOD

UA-TODDLER CEREAL BABY FOOD

UA-TODDLER FOOD

UA-TODDLER JUICE BABY FOOD

UA-TOYS BABY

UTENSILS FEEDING ACCESSORIES BABY

CARE

VALUE/ECONOMY BABY/YOUTH WIPES

VALUE/ECONOMY DISPOSABLE DIAPE

VALUE/ECONOMY DISPOSABLE DIAPERS

VALUE/ECONOMY TRAINING PANTS

DIAPOSABLE

YOUTH WIPES 


\section{APPENDIX W2}

In experimental study 4, participants listed dietary preferences, which were used to classify/restrict the data. Responses were excluded from analysis if they directly interacted with, or prevented consideration of, the nine food items in the study. Reasons indicated are listed only once below, but may have appeared in the data multiple times.

\begin{tabular}{|l|l|}
\hline \multicolumn{1}{|c|}{ Included in Analysis } & \multicolumn{1}{c|}{ Excluded from Analysis } \\
\hline None / No / etc. & Gluten-free \\
\hline $\begin{array}{l}\text { "I like fish, I like bison but ... I only buy } \\
\text { stuff on sale..." }\end{array}$ & Vegan \\
\hline "Heart healthy" & Vegetarian \\
\hline "Protein based" & No carbohydrates/ no sugar \\
\hline "Allergic to nuts and fish" & Diabetic \\
\hline & Pre-diabetic \\
\hline & Low-calorie and low carbohydrate \\
\hline & Lactose intolerant \\
\hline & Pescatarian \\
\hline & “... don't eat a lot of meat" \\
\hline
\end{tabular}

